Review

\title{
The Essential Toxin: Impact of Zinc on Human Health
}

\section{Laura M. Plum, Lothar Rink and Hajo Haase*}

Institute of Immunology, Medical Faculty, RWTH Aachen University, Pauwelstrasse 30, 52074

Aachen, Germany; E-Mails: lplum@ukaachen.de (L.M.P.); lrink@ukaachen.de (L.R.)

* Author to whom correspondence should be addressed; E-Mail: hhaase@ukaachen.de;

Tel.: +49-241-808-0205; Fax: +49-241-808-2613.

Received: 27 January 2010; in revised form: 8 March 2010 / Accepted: 10 March 2010 /

Published: 26 March 2010

\begin{abstract}
Compared to several other metal ions with similar chemical properties, zinc is relatively harmless. Only exposure to high doses has toxic effects, making acute zinc intoxication a rare event. In addition to acute intoxication, long-term, high-dose zinc supplementation interferes with the uptake of copper. Hence, many of its toxic effects are in fact due to copper deficiency. While systemic homeostasis and efficient regulatory mechanisms on the cellular level generally prevent the uptake of cytotoxic doses of exogenous zinc, endogenous zinc plays a significant role in cytotoxic events in single cells. Here, zinc influences apoptosis by acting on several molecular regulators of programmed cell death, including caspases and proteins from the $\mathrm{Bcl}$ and Bax families. One organ where zinc is prominently involved in cell death is the brain, and cytotoxicity in consequence of ischemia or trauma involves the accumulation of free zinc. Rather than being a toxic metal ion, zinc is an essential trace element. Whereas intoxication by excessive exposure is rare, zinc deficiency is widespread and has a detrimental impact on growth, neuronal development, and immunity, and in severe cases its consequences are lethal. Zinc deficiency caused by malnutrition and foods with low bioavailability, aging, certain diseases, or deregulated homeostasis is a far more common risk to human health than intoxication.
\end{abstract}

Keywords: toxicity; zinc; essential trace element 


\section{Introduction}

In the periodic table of the elements, zinc can be found in group Ilb, together with the two toxic metals cadmium and mercury. Nevertheless, zinc is considered to be relatively non-toxic to humans [1]. This is reflected by a comparison of the $\mathrm{LD}_{50}$ of the sulfate salts in rats. According to the Toxnet database of the U.S. National Library of Medicine, the oral $\mathrm{LD}_{50}$ for zinc is close to $3 \mathrm{~g} / \mathrm{kg}$ body weight, more than 10-fold higher than cadmium and 50-fold higher than mercury [2]. An important factor seems to be zinc homeostasis, allowing the efficient handling of an excess of orally ingested zinc, because after intraperitoneal injection into mice, the $\mathrm{LD}_{50}$ for zinc was only approximately four-fold higher than for cadmium and mercury [3]. In contrast to the other two metals, for which no role in human physiology is known, zinc is an essential trace element not only for humans, but for all organisms. It is a component of more than 300 enzymes and an even greater number of other proteins, which emphasizes its indispensable role for human health. Optimal nucleic acid and protein metabolism, as well as cell growth, division, and function, require sufficient availability of zinc [4].

In this review, we will give a brief summary of zinc homeostasis, followed by a description of the effects of acute zinc intoxication and the consequences of long-term exposure to elevated amounts of zinc. Besides systemic intoxication, there exists evidence for a physiological involvement of endogenous zinc in toxicity on the cellular level, e.g., regulating apoptosis in many different cell types, and having a prominent role in neuronal death. In the end, we will also briefly discuss the detrimental effects of zinc deficiency, because, unless they are exposed to zinc in the workplace or by accident, healthy individuals are at far greater risk of suffering from the adverse effects associated with zinc deficiency than from those associated with intoxication.

\section{Zinc Homeostasis}

The human body contains 2-3 g zinc, and nearly $90 \%$ is found in muscle and bone [5]. Other organs containing estimable concentrations of zinc include prostate, liver, the gastrointestinal tract, kidney, skin, lung, brain, heart, and pancreas [6-8]. Oral uptake of zinc leads to absorption throughout the small intestine and distribution subsequently occurs via the serum, where it predominately exists bound to several proteins such as albumin, $\alpha$-microglobulin, and transferrin [9].

On the cellular level, 30-40\% of zinc is localized in the nucleus, $50 \%$ in the cytosol and the remaining part is associated with membranes [4]. Cellular zinc underlies an efficient homeostatic control that avoids accumulation of zinc in excess (see also Figure 1a). The cellular homeostasis of zinc is mediated by two protein families; the zinc-importer (Zip; Zrt-, Irt-like proteins) family, containing 14 proteins that transport zinc into the cytosol, and the zinc transporter (ZnT) family, comprising 10 proteins transporting zinc out of the cytosol [10].

The same transporter families also regulate the intracellular distribution of zinc into the endoplasmic reticulum, mitochondria, and Golgi. In addition, many mammalian cell types also contain membranebound vesicular structures, so-called zincosomes. These vesicles sequester high amounts of zinc and release it upon stimulation, e.g., with growth factors [11,12]. 
Figure 1. Cellular zinc homeostasis and its impact on cytotoxicity (A) Cellular zinc homeostasis is mediated by three main mechanisms. First, by transport through the plasma membrane by importers from the Zip-family, and export proteins from the ZnT-family. Second, by zinc-binding proteins such as metallothionein. Third, by transporter-mediated sequestration into intracellular organelles, including endoplasmic reticulum, Golgi, and lysosomes. Tight control of zinc homeostasis is required for maintenance of cellular viability, whereas deregulation leads to cell death. (B) A particular role in intracellular zinc homeostasis is played by the metallothionein/thionein-system. Free and loosely bound zinc ions are bound by the apo-protein thionein (Tred), to form metallothionein (MT). Elevated levels of free zinc ions can bind to zinc finger structures of the metal-regulatory transcription factor (MTF)-1, thus inducing the expression of thionein. Additionally, oxidation of thiols by reactive oxygen (ROS) or nitrogen (RNS) species triggers the formation of the oxidized protein thionin (Tox) with concomitant release of zinc.

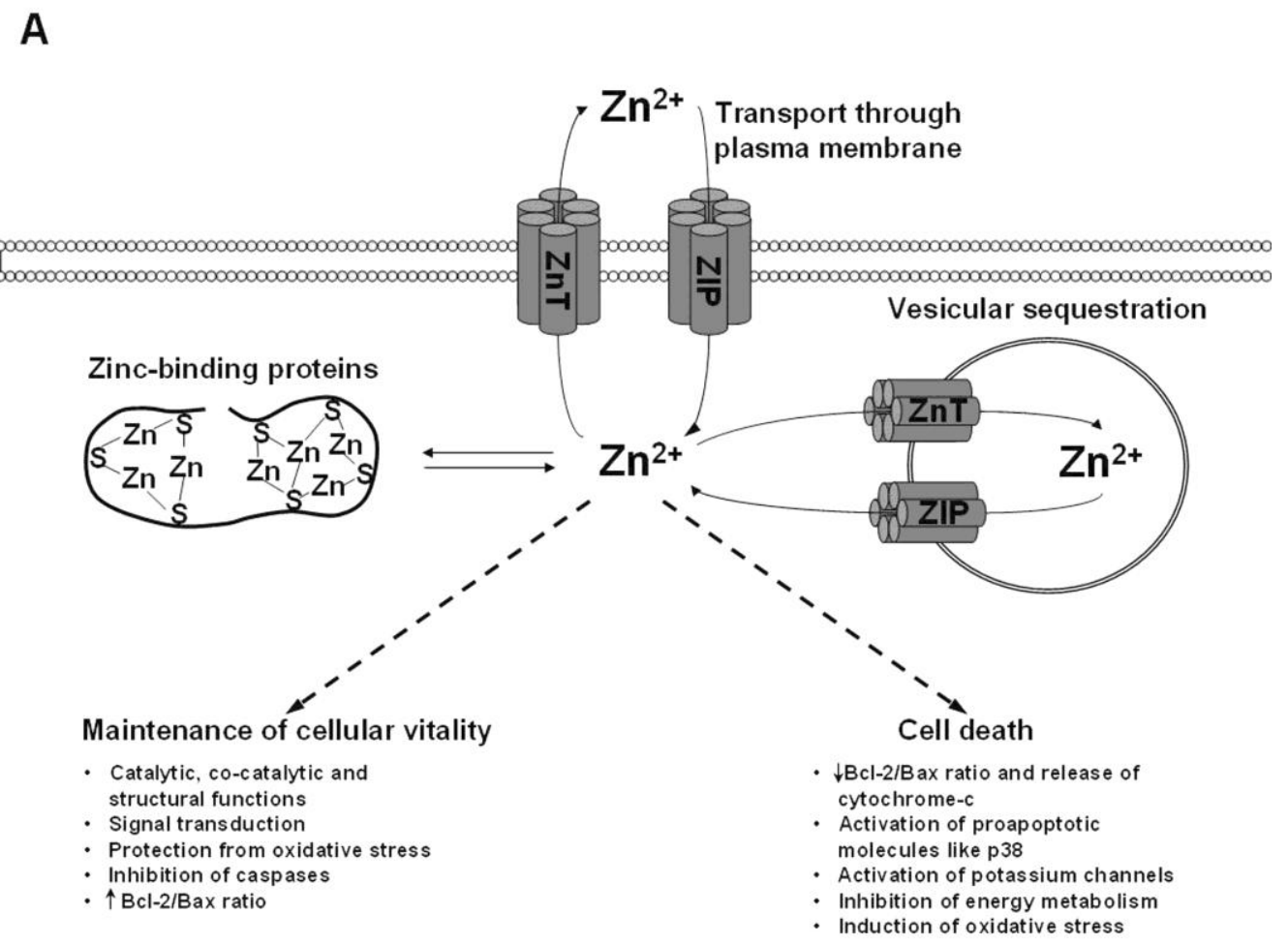

B

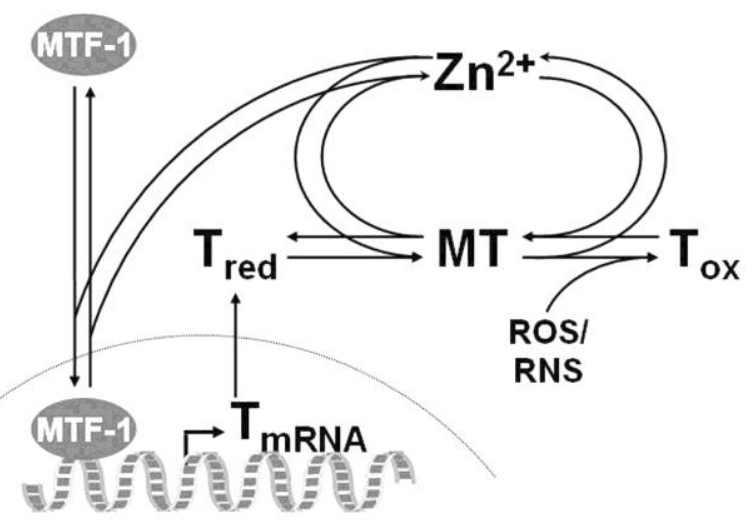


Finally, metallothioneins (MTs) play a significant role in zinc homeostasis by complexing up to $20 \%$ of intracellular zinc (Figure 1b) [13,14]. MTs are ubiquitous proteins, characterized by a low-molecular weight of 6-7 kDa, high cysteine content, and their ability to complex metal ions. One MT molecule can bind up to seven zinc ions. Through different affinities of the metal ion binding sites, it can act as a cellular zinc buffer over several orders of magnitude [15]. Dynamic regulation of cellular zinc by MT results from the synthesis of the apo-form thionein (T) in response to elevated intracellular zinc levels by triggering the metal response element-binding transcription factor (MTF)-1 [16]. In addition, oxidation of cysteine residues can alter the number of metal binding thiols, connecting redox and zinc metabolism. An in-depth discussion of this complex subject can be found in a recent review [17].

\section{Exposure to Zinc}

There are three major routes of entry for zinc into the human body; by inhalation, through the skin, or by ingestion [18]. Each exposure type affects specific parts of the body (Figure 2) and allows the uptake of different amounts of zinc.

\subsection{Exposure by Inhalation}

Inhalation of zinc-containing smoke generally originates from industrial processes like galvanization, primarily affecting manufacture workers. In addition, military smoke bombs contain zinc oxide or zinc chloride, making soldiers a group in which several cases of inhalation of zinc-containing fumes were described. For example, Homma and colleagues reported a case of two soldiers who developed adult respiratory distress syndrome (ARDS) upon exposure to a zinc chloride-containing smoke bomb [19]. The two men died 25 and 32 days after the accident, respectively. Another soldier was exposed to concentrated zinc chloride for several minutes during military training [20]. He also developed ARDS $48 \mathrm{~h}$ after exposure. After tracheal intubation and mechanical ventilation for eight days, he left the hospital, and four months after the incident he returned to work without any respiratory disorder [20]. There are a few additional reports of related incidents with smoke bombs having similar effects on the respiratory tract $[21,22]$.

However, in none of the incidents there was unequivocal evidence that zinc was the main cause for the respiratory symptoms. Not only was no information about the concentrations available, but also the inhaled smoke contained several other ingredients besides zinc chloride. In addition, zinc chloride is generally caustic, so the effects could have risen from the specific properties of the compound, rather than being a direct effect of zinc intoxication.

The most widely known effect of inhaling zinc-containing smoke is the so-called metal fume fever (MFF), which is mainly caused by inhalation of zinc oxide. This acute syndrome is an industrial disease which mostly occurs by inhalation of fresh metal fumes with a particle size $<1 \mu \mathrm{m}$ in occupational situations such as zinc smelting or welding [23]. Symptoms of this reversible syndrome begin generally a few hours after acute exposure and include fever, muscle soreness, nausea, fatigue, and respiratory effects like chest pain, cough, and dyspnea [24]. The respiratory symptoms have been shown to be accompanied by an increase in bronchiolar leukocytes [23]. In general, MFF is not life-threatening and the respiratory effects disappear within one to four days [25]. 
Development of MFF is connected to the exposure level, but very little data is available concerning the zinc concentrations that trigger this syndrome [26]. Two volunteers developed MFF as a consequence of acute inhalation (10-12 minutes) of $600 \mathrm{mg} z i n c / \mathrm{m}^{3}$ as zinc oxide [27]. Hammond and colleagues reported about workers who had shortness of breath and chest pain 2-12 hours following exposure to $320-580 \mathrm{mg}$ zinc $/ \mathrm{m}^{3}$ as zinc oxide [28]. Only small changes in forced expiratory flow were observed after exposure to $77 \mathrm{mg}$ zinc/ $\mathrm{m}^{3}$ (15-30 minutes) as zinc oxide [29]. Several reports of exposures to lower concentrations of zinc oxide $\left(14 \mathrm{mg} / \mathrm{m}^{3}\right.$ for eight hours, $8-12 \mathrm{mg} \mathrm{zinc} / \mathrm{m}^{3}$ for up to three hours and $0.034 \mathrm{mg}$ zinc $/ \mathrm{m}^{3}$ for six to eight hours) did not result in symptoms of metal fume fever $[28,30,31]$. Today, the permissible exposure limit according to the Occupational Safety and Health Administration (OSHA) is $5 \mathrm{mg} / \mathrm{m}^{3}$ for zinc oxide (dusts and fumes) in workplace air during an 8-hour workday, 40-hour work week [32].

Figure 2. Comparison of the effects of zinc intoxication versus deficiency. Intoxication by excessive exposure to, or intake of, zinc (left hand side), and deprivation of zinc by malnutrition or medical conditions (right hand side), have detrimental effects on different organ systems. Effects that could not be attributed to a certain organ system or affect several organs are classified as systemic symptoms.

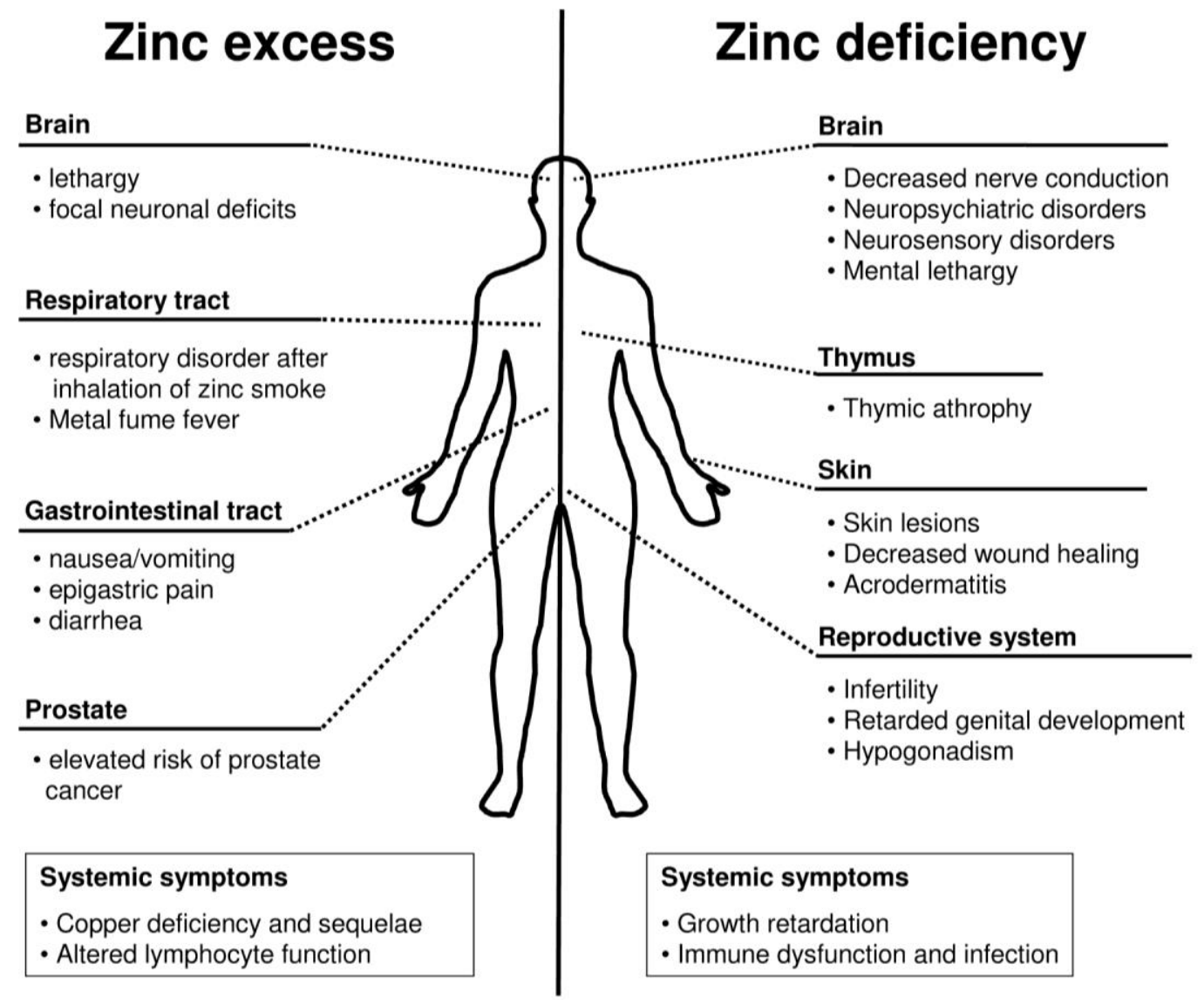




\subsection{Dermal Exposure}

Dermal absorption of zinc occurs, but the number of studies is limited and the mechanism is still not clearly defined. Agren and colleagues pointed out that the $\mathrm{pH}$ of the skin, the amount of zinc applied, and its chemical speciation influence the absorption of zinc [33,34].

In a study in which a $25 \%$ zinc oxide patch $\left(2.9 \mathrm{mg} / \mathrm{cm}^{2}\right)$ was placed on human skin for 48 hours, there was no evidence of dermal irritation [33]. In another study comparing the dermal effect of different zinc compounds in mice, rabbits, and guinea pigs, zinc chloride was clearly the strongest irritant, followed by zinc acetate, causing moderate, and zinc sulfate, causing low irritations. Consistent with the study by Agren, zinc oxide did not show any irritant effect on skin [35].

As mentioned above, zinc chloride is caustic, and the irritation does not necessarily indicate a toxic effect of zinc. In contrast to a potentially harmful effect of zinc on skin, it should be noted that zinc is a well-known supplement for topical treatment of wounds and several dermatological conditions [34,36-38]. Based on the existing data, it can be concluded that dermal exposure to zinc does not constitute a noteworthy toxicological risk.

\subsection{Oral Exposure}

Due to its nature as an essential trace element, oral uptake of small amounts of zinc is essential for survival. The recommended dietary allowance (RDA) for zinc is $11 \mathrm{mg} /$ day for men and $8 \mathrm{mg} /$ day for women [39]. Lower zinc intake is recommended for infants (2-3 mg/day) and children (5-9 mg/day) because of their lower average body weights [39]. This is significantly below the $\mathrm{LD}_{50}$ value, which has been estimated to be $27 \mathrm{~g}$ zinc/day humans based on comparison with equivalent studies in rats and mice [18]. In general, uptake of such an amount is unlikely, because approximately 225-400 mg zinc have been determined to be an emetic dose [40]. However, there is one published report of a woman who died after oral intake of $28 \mathrm{~g}$ zinc sulfate. After ingestion, she started vomiting and developed tachycardia as well as hyperglycemia. She died five days later of hemorrhagic pancreatitis and renal failure [41].

Immediate symptoms after uptake of toxic amounts of zinc include abdominal pain, nausea, and vomiting. Additional effects include lethargy, anemia, and dizziness [42]. Particular effects of excessive oral zinc exposure are discussed in detail below.

\section{Gastrointestinal Effects}

The gastrointestinal tract is directly affected by ingested zinc, before it is distributed through the body. Therefore, multiple gastrointestinal symptoms after oral uptake of zinc have been reported. Brown et al. described several cases in which high zinc ingestion resulted from storage of food or drink in galvanized containers. Ingestion was caused by the moderately acidic nature of the food or drink, enabling the removal of sufficient zinc from the galvanized coating. The resulting symptoms included nausea and vomiting, epigastric pain, abdominal cramps, and diarrhea [40].

In a study by Samman and Roberts, symptoms such as abdominal cramps, vomiting and nausea occurred in 26 of 47 healthy volunteers following ingestion of zinc sulfate tablets, containing $150 \mathrm{mg}$ 
elemental zinc, for six weeks [43]. However, similar doses have been used in several other zinc supplementation studies without comparable side effects [44].

In addition to zinc sulfate, other zinc compounds like zinc oxide and zinc gluconate also have a similar impact on the gastrointestinal system [45-47]. A 39-year-old man showed nausea, vomiting, and abdominal pain six hours after ingesting $150 \mathrm{~g}$ of a $10 \%$ zinc oxide lotion, but without signs of systemic toxicity. Furthermore, he developed gastroduodenal corrosive injury. The symptoms persisted for three days and on the fifth day of admission, the corrosive injury showed regression without cicatrization [47].

\section{Zinc-Induced Copper Deficiency}

Taking up large doses of supplemental zinc over extended periods of time is frequently associated with copper deficiency [48-50]. This correlation seems to be caused by the competitive absorption relationship of zinc and copper within enterocytes, mediated by MT. The expression of MT is upregulated by high dietary zinc content, and MT binds copper with a higher affinity than zinc. Consequently, available copper ions are bound by MT and the resulting complex is subsequently excreted [51,52]. Oestreicher and Cousins stated that the dietary intake of different doses of copper and zinc did not significantly alter the absorption of the other metal, as long as they were given at the same ratio, irrespective if $1 \mathrm{mg} / \mathrm{kg}$ copper and $5 \mathrm{mg} / \mathrm{kg}$ zinc, or up to $36 \mathrm{mg} / \mathrm{kg}$ copper together with $180 \mathrm{mg} / \mathrm{kg}$ zinc were given [53]. Nevertheless, copper absorption is depressed when zinc is given in high excess over copper [54].

Frequent symptoms of copper deficiency include hypocupremia, impaired iron mobilization, anemia, leukopenia, neutropenia, decreased superoxide dismutase (SOD) (particularly erythrocyte SOD (ESOD)), ceruloplasmin as well as cytochrome-c oxidase, but increased plasma cholesterol and LDL:HDL cholesterol and abnormal cardiac function [55-57].

Furthermore, Irving and colleagues reported the case of a 19-year old woman who was supplemented with two doses of $50 \mathrm{mg}$ zinc per day as part of a treatment of Hallervorden-Spatz syndrome, leading to a total daily intake of about $121.25 \mathrm{mg}$ of zinc for more than 5 years, corresponding to approximately 15 times the RDA. Her daily intake of copper was $2 \mathrm{mg}$, which was approximately twice the RDA. As a result, she was markedly anemic and had severe neutropenia. Zincinduced copper deficiency was confirmed by elevated serum zinc and low copper and ceruloplasmin serum levels. Four weeks after zinc therapy was stopped, all hematological and trace-metal parameters showed strong trends toward normalization and were normal after eight months [58].

Prasad and colleagues reported several cases of patients with sickle cell anemia who received $150 \mathrm{mg}$ zinc/day and consequently showed low plasma copper, low ceruloplasmin, leukopenia, and anemia [59]. Another case report described a 31-year-old schizophrenic man who had been ingesting coins for 10 years [60]. He entered the hospital with symptoms including nausea, vomiting, and abdominal pain. Furthermore, profound anemia, neutropenia, and virtually absent serum copper and ceruloplasmin levels together with elevated zinc levels were diagnosed. Upon X-ray examination a large number of coins (totaling \$22.50) were identified and surgically removed. Following the surgery, anemia and copper deficiency rapidly resolved. His copper deficiency was attributed to the ingestion of pennies, which since 1982 are composed of $98 \%$ zinc and 2\% copper [60]. Several additional reports 
of zinc-induced copper deficiency leading to anemia and several other cytopenias were reviewed by Fiske and colleagues [55].

The mechanism by which copper deficiency induces anemia is based on the requirement of copper for several enzymes involved in iron transport and utilization and, therefore, in heme synthesis. For example, ceruloplasmin is a ferroxidase that binds copper and converts ferrous to ferric iron, allowing it to bind to transferrin and be transported. Cytochrome-c oxidase is also dependent on copper, and is required for the reduction of ferric iron to be incorporated into the heme molecule [61-63]. In addition to interference with heme synthesis, copper deficiency causes approximately $85 \%$ reduction of ESOD in the red blood cell (RBC) membrane, decreasing RBC survival time [64].

Whereas a recent meta-analysis found no general effect of zinc supplementation on serum lipoproteins [65], it may occur as a consequence of disturbed copper homeostasis. Copper deficiency is related to alterations of serum cholesterol levels [57]. In healthy men, a daily intake of $160 \mathrm{mg}$ zinc/day decreased HDL cholesterol significantly [66,67]. Also, young women who ingested $100 \mathrm{mg}$ zinc/day showed a reduction in HDL cholesterol [68]. A study with 24 men who were fed omnivorous diets that were deficient in copper $(0.89 \mathrm{mg})$ and high in zinc $(21.4 \mathrm{mg})$, i.e., a $\mathrm{Zn}: \mathrm{Cu}$ ratio of 23.5 , showed low plasma copper, ESOD and HDL cholesterol, while LDL cholesterol was elevated [69]. This study was stopped after 11 weeks because four participants experienced cardiac abnormalities. Klevay and colleagues fed one man an omnivorous diet providing a $\mathrm{Zn}$ to copper ratio $\geq 16$ for 105 days. Plasma copper and ceruloplasmin decreased, whereas total cholesterol and LDL cholesterol increased [70]. This experiment was ended when arrhythmia was detected. Taking into account several additional studies, Sandstead suggested that cardiac abnormalities were associated with $\mathrm{Zn}$ to copper ratios $\geq 16$ [57].

\section{Zinc Supplementation and Cancer}

Whereas several other metals are well-known carcinogens, zinc is not generally considered to be a causative agent for cancer development. In contrast, displacement of zinc from zinc-binding structures, e.g., finger structures in DNA repair enzymes, may even be a major mechanism for carcinogenicity of other metals such as cadmium, cobalt, nickel, and arsenic [71].

One well investigated example in which an involvement of zinc in cancer development was suggested is prostate cancer. Notably, zinc levels in prostate adenocarcinoma are significantly lower than in the surrounding normal prostate tissues, suggesting an implication of zinc in the pathogenesis and progression of prostate malignancy [72-74]. This is based on a down regulation of the zinc transporter Zip1, which is responsible for zinc uptake and accumulation in prostate cells [75,76].

Men with moderate to higher zinc intake may have a lower risk for prostate cancer, but the opposite may be true at extremely high doses and long-term supplementation [77]. A study by Leitzmann and colleagues examined the association between supplemental zinc intake and prostate cancer risk among 46,974 U.S. men. During 14 years, 2901 new cases of prostate cancer were observed, of which 434 were diagnosed as advanced cancer. Supplemental zinc intake at doses of up to $100 \mathrm{mg} /$ day did not cause a higher prostate cancer risk, whereas long-term supplementation with higher doses increased the relative risk 2.9-fold [78]. This increased risk may not be due to direct carcinogenicity of zinc, because 
it is known that immunosuppression significantly increases the incidence of cancer, and, as discussed in the following paragraph, high doses of zinc can be immunosuppressive.

\section{Immunological Effects}

Sufficient availability of zinc is of particular importance to the immune system. Thereby, it plays a key role in multisided cellular and molecular mechanisms [79,80]. For instance, zinc influences the lymphocyte response to mitogens and cytokines, serves as a co-factor for the thymic hormone thymulin, and is involved in leukocyte signal transduction [81-83]. An influence of zinc excess on $\mathrm{T}$ cell function was observed in several in vitro studies. In cell culture, very high zinc concentrations (above $100 \mu \mathrm{M}$ ) in a serum-free culture medium stimulate monocytes to secrete pro-inflammatory cytokines [84], but actually inhibit $\mathrm{T}$ cell functions. In general, $\mathrm{T}$ cells have a lower intracellular zinc concentration and are more susceptible to increasing zinc levels than monocytes [85,86]. Also, in vitro alloreactivity was inhibited in the mixed lymphocyte reaction (MLC) after treatment with more than $50 \mu \mathrm{M}$ zinc [87]. A similar inhibition was observed when the MLC was done ex vivo with cells from individuals that had been supplemented with $80 \mathrm{mg}$ zinc per day for one week, indicating that zinc supplementation has the potential to suppress the allogeneic immune response at relatively low doses [88].

An in vivo study supported the finding that zinc excess can affect lymphocyte function. 83 healthy volunteers ingested $330 \mathrm{mg}$ zinc/ day in three doses for a month. The treatment had a small but significant influence on the lymphocyte response to the mitogens phytohemagglutinin (PHA) and Concanavalin A (Con A). Interestingly, it was observed that zinc had an immuno-regulatory influence, i.e., it decreased the lymphocyte response in high responders and had an enhancing effect on low responders [89].

\section{The Role of Zinc in Cell Death}

In addition to the systemic toxic effects of zinc, this metal is also involved in the regulation of live and death decisions on the cellular level. First, we will discuss its role in apoptosis. Second, we will focus on an organ where zinc toxicity has been investigated in great detail, the brain.

\subsection{Impact of Zinc on Apoptosis}

The exact role of zinc in the regulation of apoptosis is ambiguous. A variety of studies indicate that, depending on its concentration, zinc can either be pro- or anti-apoptotic, and both, zinc deprivation and excess, can induce apoptosis in the same cell line [90-93].

The induction of apoptosis by high levels of intracellular zinc has been shown in different tissues and cell types [93-95]. Reports indicate that accumulation of intracellular zinc, either as a consequence of exogenous administration or release from intracellular stores by reactive oxygen species or nitrosation, activates pro-apoptotic molecules like p38 and potassium channels, leading to cell death [93,96-98]. Increased intracellular zinc levels may also induce cell death by inhibition of the energy metabolism [99,100]. 
Sensitive targets of zinc toxicity are the anti-apoptotic Bcl-2-like and pro-apoptotic Bax-like mitochondrial membrane proteins. In context of its apoptosis-inducing properties, zinc has been shown to increase the expression of Bax, leading to a decrease in the Bcl-2/Bax ratio [101]. As a consequence, dissipation of the mitochondrial membrane potential leads to the release of cytochrome-c from mitochondria into the cytosol [96,102-105].

The anti-apoptotic properties of zinc likely comprise two main mechanisms. First, zinc limits the extent of damage induced during oxidative stress, thereby suppressing signaling pathways resulting in apoptosis. Second, zinc directly affects several proteins and pathways that regulate apoptosis.

Consistent with the first issue, zinc deficiency has been shown to induce oxidative stress [106-108]. Mechanisms by which the redox-inert zinc protects cells against oxidative damage seem to include its property to protect sulfhydryl groups in proteins from oxidation [109]. Furthermore, by stabilizing lipids and proteins, zinc can preserve cellular membranes and macromolecules from oxidative damage. On the other hand, it has to be noted that elevated availability of zinc may also induce oxidative stress, and its impact on redox homeostasis may either be protective or promoting, depending on its availability [17].

With regard to the second mechanism, interaction of zinc with several apoptosis-regulating molecules has been reported. Zinc is a potent caspase-3 inhibitor [110] with an $\mathrm{IC}_{50}$ below $10 \mathrm{nM}$ [111]. Furthermore, inhibition of caspases-6, -7, and -8 at low zinc concentrations was also shown, with caspase- 6 being the most sensitive of the three [112].

Zinc deficiency can also induce apoptosis by disrupting growth factor signaling molecules such as ERK and Akt [113]. Other molecular targets for zinc are the anti-apoptotic Bcl-2-like and proapoptotic Bax-like mitochondrial membrane proteins. Zinc has been shown to increase the Bcl-2/Bax ratio, thereby increasing the resistance of the cells to apoptosis [114]. Consistent with this, in a study by Zalewski and colleagues apoptosis was induced in premonocytic cells by treatment with hydrogen peroxide. Supplementation with $1 \mathrm{mM}$ zinc increased the ratio of Bcl-2 to Bax resulting in the inhibition of active caspase-3 and reduction of apoptosis [115]. Zinc-mediated apoptosis is abrogated by chelation with TPEN [116]. This is not undisputed, because it has also been shown in another study that zinc can increase the expression of Bax, leading to an decreased Bcl-2/Bax ratio and the release of cytochrome-c from mitochondria [101].

The influence of zinc on apoptosis is very complex and data are in part even contradictory. Amongst others, variables in this complex network are tissue and cell type, zinc concentration, expression of zinc transporters and zinc-binding proteins, other environmental circumstances like oxidative or nitrosative stress, and the involvement of multiple molecular targets with opposing functions.

\subsection{Role of Zinc in Neuronal Death}

A prominent and well investigated example for the control that zinc exerts on survival on the cellular level is the brain. This will now be discussed in more detail as an example of the mechanisms by which zinc can influence cellular survival.

Normally, homeostatic mechanisms should prevent zinc from accumulating in the brain to reach toxic concentrations as a result of excessive oral ingestion. However, there are reports of neurological 
symptoms following zinc intoxication, e.g., of a boy who showed lethargy and focal neurological deficits three days after he ingested $12 \mathrm{~g}$ of metallic zinc [117].

Many studies indicate that zinc acts as a neuromodulator [118-121]. On the other hand, experimental evidence indicates that endogenous zinc might be a relatively potent, rapidly acting neurotoxin, and, to a lesser extent, also a gliotoxin [122-126].

Zinc is stored in and released from vesicles in presynaptic terminals of a specific subset of neurons that also releases glutamate. Therefore, these neurons are defined as "gluzinergic" neurons [119, 127]. Zinc can be released from presynaptic terminals during synaptic transmission, enabling it to enter postsynaptic somata and dendrites of cells via zinc-permeable ion channels [105]. These channels include NMDA (N-methyl-D-aspartate)-gated channels [128], voltage-gated calcium channels $[129,130]$ and the calcium-permeable AMPA ( $\alpha$-amino-3-hydroxy-5-methyl-4-isoxazole propionic acid)/kainate channel [131,132].

In addition to being sequestered in vesicles of presynaptic terminals in the gluzinergic neurons, zinc can also be bound to MT, especially MT-III, in perikarya as well as being taken up by mitochondria [133]. The MT-III isoform is found only in the brain and it is abundant in the gluzinergic neurons $[134,135]$.

Exposure to $300-600 \mu \mathrm{M}$ zinc for 15 minutes results in extensive neuronal death in cortical cell culture [136]. Considering that neurons store high amounts of free zinc in their terminals [137] that are released upon depolarization [138,139], zinc may play an active role in neuronal injury. Furthermore, membrane depolarization, which is associated with acute brain injury [140], greatly increases the potency of zinc to act as a neurotoxin [141]. Weiss et al. confirmed this by showing that depolarization with high concentrations $(25 \mathrm{mM})$ of potassium media requires just a five minute-exposure to $100 \mu \mathrm{M}$ zinc to kill all neurons in cortical cell culture [131].

Zinc has been described as a critical component of the excitotoxic cascade occurring after ischemia, seizures, and head trauma [141-143]. The first study providing evidence that zinc accumulation may play a role in the selective death of dentate hilar neurons after global ischemia in rats was done by Tonder and colleagues [144]. In the meantime, zinc accumulation in dying or dead neurons has not only been shown in the hippocampal hilar region, but also in all brain regions damaged in global ischemia such as hippocampal CA1, neocortex, thalamus, and striatum [145]. Consistent with the hypothesis that zinc-accumulation may lead to neuronal cell death, this event was prevented by the intraventricular injection of the zinc-chelating agent CaEDTA [145].

Zinc release and accumulation of zinc ions was also observed in a rat model of traumatic brain injury, where Suh and colleagues showed that trauma is associated with loss of zinc from presynaptic boutons and appearance of zinc in injured neurons. Again, neuroprotection occurred by intraventricular administration of a zinc chelator [146].

For some time, vesicular zinc was thought to be the only releasable pool of zinc in the brain [127]. This led to the assumption that the zinc ions accumulating in injured neurons must be entirely of presynaptic origin [127], but when ZnT-3 knock-out mice were investigated, which lack histochemically reactive zinc in synaptic vesicles, they still showed zinc accumulation in degenerating neurons, pointing toward sources other than synaptic vesicular zinc [147]. Alternative dynamic zinc sources might be MT-III as well as mitochondrial stores in the postsynaptic neurons $[148,149]$. 
Although zinc is redox-inactive in biological systems and exists only as a bivalent cation, there is evidence that zinc toxicity in neurons is mediated mainly by oxidative stress [141]. Zinc-induced cell death is associated with increased levels of reactive oxygen species in neurons $[150,151]$. In addition, free-radical-generating enzymes like NADPH oxidase are induced and activated by exposure to zinc [152]. Finally, zinc-induced cell death has been shown to be attenuated by various antioxidant interventions [96,153].

Besides oxidative stress, nitrosative stress can also affect zinc-induced neuronal injury. Nitric monoxide plays a crucial role in zinc toxicity by releasing zinc ions from MT [154], and inhibition of nitric oxide synthase significantly reduces zinc release from brain slices during oxygen and glucose deprivation [155]. Consistent with this, Frederickson and colleagues observed that nitric oxide also rapidly releases zinc from presynaptic terminals [156].

In addition to the impact of zinc on apoptosis discussed above, zinc-induced apoptosis in neurons might be based on two additional mechanisms. First, zinc-exposed neurons show an induction of the neutrophin receptor $\mathrm{p} 75^{\mathrm{NTR}}$ and $\mathrm{p} 75^{\mathrm{NTR}}$-associated death executor (NADE) [157], a combination that can trigger caspase activation and apoptosis [158]. Second, high intracellular zinc concentrations trigger dysfunction of neuronal mitochondria, resulting in the release of pro-apoptotic proteins such as cytochrome-c and apoptosis-inducing factor (AIF) [148].

Although the release of intracellular zinc triggers neuronal apoptosis [96,159,160], indicators of necrosis such as cell body swelling and destruction of intracellular organelles have also been observed [96,150], indicating that zinc-induced neuronal cell death might encompass both apoptotic and necrotic mechanisms [143]. Taken together, alterations of neuronal zinc homeostasis have a profound influence on cellular survival during acute insults, and zinc chelators are discussed as potential therapeutic agents for the treatment of stroke [161].

It seems likely that zinc is also involved in neurodegenerative diseases, e.g., zinc and a deregulated zinc homeostasis could be important to onset and progression of Alzheimer's disease [162]. Here, the use of metal chelators such as clioquinol to restore normal neuronal zinc homeostasis has shown promising results in vivo [163].

\section{Zinc Deficiency}

As discussed above, systemic zinc toxicity is not a major health problem. On the other hand, due to its essentiality, a lack of this trace element leads to far more severe and widespread problems. Both, nutritional and inherited zinc deficiency generate similar symptoms [164], and clinical zinc deficiency causes a spectrum from mild and marginal effects up to symptoms of severe nature (Figure 2) [165].

Human zinc deficiency was first reported in 1961, when Iranian males were diagnosed with symptoms including growth retardation, hypogonadism, skin abnormalities, and mental lethargy, attributed to nutritional zinc deficiency [166]. Later studies with some Egyptian patients showed remarkably similar clinical features [167]. Additional studies in the ongoing years manifested zinc deficiency as a potentially widespread problem in developing as well as in industrialized nations [168].

Severe zinc deficiency can be either inherited or acquired. The most severe of the inherited forms is acrodermatitis enteropathica, a rare autosomal recessive metabolic disorder resulting from a mutation in the intestinal Zip4 transporter [169]. Symptoms of this condition include skin lesions, alopecia, 
diarrhea, neuropsychological disturbances, weight loss, reduced immune function, as well as hypogonadism in men, and can be lethal in the absence of treatment [170].

Acquired severe zinc deficiency has been observed in patients receiving total parental nutrition without supplementation of zinc, following excessive alcohol ingestion, severe malabsorption, and iatrogenic causes such as treatment with histidine or penicillamine [165]. The symptoms are mostly similar to those arising during acrodermatitis enteropathica.

Some reports indicate the existence of another group of inherited disorders of zinc metabolism. They lead to baseline zinc plasma levels above $300 \mu \mathrm{g} / 100 \mathrm{~mL}$, more than three times the physiological level, while iron and copper levels stay normal [171-173]. Even though this exceeds the amount normally found in serum after zinc intoxication, symptoms range from none to severe anemia, growth failure, and systemic inflammation, and resemble zinc deficiency rather than chronic or acute intoxication [172-175]. The elevated zinc levels have been attributed to excessive binding to serum proteins, e.g., by albumin [171,173], or to overexpression of the zinc-binding S100 protein calprotectin $[172,174]$. Hence, the large amounts of zinc in the serum of these patients are sequestered by proteins, potentially even depleting biologically available zinc [175].

Clinical manifestations of moderate zinc deficiency are mainly found in patients with low dietary zinc intake, alcohol abuse, malabsorption, chronic renal disease, and chronic debilitation. Symptoms include growth retardation (in growing children and adolescents), hypogonadism in men, skin changes, poor appetite, mental lethargy, delayed wound healing, taste abnormalities, abnormal dark adaptation, and anergy [165].

Moderate zinc deficiency can also occur as a consequence of sickle cell disease [176]. Hyperzincuria and a high protein turnover due to increased hemolysis lead to moderate zinc deficiency in these patients, which causes clinical manifestations typical for zinc deficiency, such as growth retardation, hypogonadism in males, hyperammonemia, abnormal dark adaptation, and cell-mediated immune disorder [177] connected with thymic atrophy [178].

In mild cases of zinc deficiency, slight weight loss, oligospermia and hyperammonemia were observed [165]. One population in which mild zinc deficiency occurs with high prevalence, even in industrialized countries, are the elderly. Here, a significant proportion has reduced serum zinc levels, and zinc supplementation studies indicate that this deficiency contributes significantly to increased susceptibility to infectious diseases [44].

The overall frequency of zinc deficiency worldwide is expected to be higher than 20\% [179]. In developing countries, it may affect more than 2 billion people [166,180-182]. Furthermore, it has been estimated that only $42.5 \%$ of the elderly ( $\geq 71$ years) in the Unites States have adequate zinc intake [183]. This widespread occurrence combined with the variety of clinical manifestations makes zinc deficiency a serious nutritional problem, which has a far greater impact on human health than the relatively infrequent intoxication with zinc.

\section{Conclusions}

Zinc is an essential trace element, and the human body has efficient mechanisms, both on systemic and cellular levels, to maintain homeostasis over a broad exposure range. Consequently, zinc has a 
rather low toxicity, and a severe impact on human health by intoxication with zinc is a relatively rare event.

Nevertheless, on the cellular level zinc impacts survival and may be a crucial regulator of apoptosis as well as neuronal death following brain injury. Although these effects seem to be unresponsive to nutritional supplementation with zinc, future research may allow influencing these processes via substances that alter zinc homeostasis, instead of directly giving zinc.

Whereas there are only anecdotal reports of severe zinc intoxication, zinc deficiency is a condition with broad occurrence and potentially profound impact. Here, the application of "negative zinc", i.e., substances or conditions that deplete the body of zinc, constitute a major health risk. The impact ranges from mild zinc deficiency, which can aggravate infections by impairing the immune defense, up to severe cases, in which the symptoms are obvious and cause reduced life expectancy.

\section{References}

1. Fosmire, G.J. Zinc toxicity. Am. J. Clin. Nutr. 1990, 51, 225-227.

2. U.S. National Library of Medicine, Toxnet Database. Available online: http://toxnet.nlm.nih.gov (accessed January 21, 2010).

3. Jones, M.M.; Schoenheit, J.E.; Weaver, A.D. Pretreatment and heavy metal LD50 values. Toxicol. Appl. Pharmacol. 1979, 49, 41-44.

4. Vallee, B.L.; Falchuk, K.H. The biochemical basis of zinc physiology. Physiol. Rev. 1993, 73, 79-118.

5. Wastney, M.E.; Aamodt, R.L.; Rumble, W.F.; Henkin, R.I. Kinetic analysis of zinc metabolism and its regulation in normal humans. Am. J. Physiol. 1986, 251, R398-R408.

6. Bentley, P.J.; Grubb, B.R. Experimental dietary hyperzincemia tissue disposition of excess zinc in rabbits. Trace. Elem. Med. 1991, 8, 202-207.

7. He, L.S.; Yan, X.S.; Wu, D.C. Age-dependent variation of zinc-65 metabolism in LACA mice. Int J. Radiat. Biol. 1991, 60, 907-916.

8. Llobet, J.M.; Domingo, J.L.; Colomina, M.T.; Mayayo, E.; Corbella, J. Subchronic oral toxicity of zinc in rats. Bull. Environ. Contam. Toxicol. 1988, 41, 36-43.

9. Scott, B.J.; Bradwell, A.R. Identification of the serum binding proteins for iron, zinc, cadmium, nickel, and calcium. Clin. Chem. 1983, 29, 629-633.

10. Lichten, L.A.; Cousins, R.J. Mammalian zinc transporters: nutritional and physiologic regulation. Annu. Rev. Nutr. 2009, 29, 153-176.

11. Haase, H.; Maret, W. Intracellular zinc fluctuations modulate protein tyrosine phosphatase activity in insulin/insulin-like growth factor-1 signaling. Exp. Cell Res. 2003, 291, 289-298.

12. Taylor, K.M.; Vichova, P.; Jordan, N.; Hiscox, S.; Hendley, R.; Nicholson, R.I. ZIP7-mediated intracellular zinc transport contributes to aberrant growth factor signaling in antihormoneresistant breast cancer Cells. Endocrinology 2008, 149, 4912-4920.

13. Chimienti, F.; Aouffen, M.; Favier, A.; Seve, M. Zinc homeostasis-regulating proteins: new drug targets for triggering cell fate. Curr. Drug Targets 2003, 4, 323-338.

14. Tapiero, H.; Tew, K.D. Trace elements in human physiology and pathology: zinc and metallothioneins. Biomed. Pharmacother. 2003, 57, 399-411. 
15. Krezel, A.; Maret, W. Dual nanomolar and picomolar $\mathrm{Zn}(\mathrm{II})$ binding properties of metallothionein. J. Am. Chem. Soc. 2007, 129, 10911-10921.

16. Laity, J.H.; Andrews, G.K. Understanding the mechanisms of zinc-sensing by metal-response element binding transcription factor-1 (MTF-1). Arch. Biochem. Biophys. 2007, 463, 201-210.

17. Maret, W. Zinc coordination environments in proteins as redox sensors and signal transducers. Antioxid. Redox. Signal 2006, 8, 1419-1441.

18. Toxicological Profile for Zinc. Agency for Toxic Substances and Disease Registry Division of Toxicology and Environmental Medicine: Atlanta, GA, USA, 2005.

19. Homma, S.; Jones, R.; Qvist, J.; Zapol, W.M.; Reid, L. Pulmonary vascular lesions in the adult respiratory distress syndrome caused by inhalation of zinc chloride smoke: a morphometric study. Hum. Pathol. 1992, 23, 45-50.

20. Freitag, A.; Caduff, B. ARDS caused by military zinc fumes exposure. Schweiz Med. Wochenschr. 1996, 126, 1006-1010.

21. Johnson, F.A.; Stonehill, R.B. Chemical pneumonitis from inhalation of zinc chloride. Dis. Chest 1961, 40, 619-624.

22. Zerahn, B.; Kofoed-Enevoldsen, A.; Jensen, B.V.; Molvig, J.; Ebbehoj, N.; Johansen, J.S.; Kanstrup, I.L. Pulmonary damage after modest exposure to zinc chloride smoke. Respir. Med. 1999, 93, 885-890.

23. Vogelmeier, C.; Konig, G.; Bencze, K.; Fruhmann, G. Pulmonary involvement in zinc fume fever. Chest 1987, 92, 946-948.

24. Rohrs, L.C. Metal-fume fever from inhaling zinc oxide. AMA Arch. Ind. Health 1957, 16, 42-47.

25. Brown, J.J. Zinc fume fever. Br. J. Radiol. 1988, 61, 327-329.

26. Martin, C.J.; Le, X.C.; Guidotti, T.L.; Yalcin, S.; Chum, E.; Audette, R.J.; Liang, C.; Yuan, B.; Zhang, X.; Wu, J. Zinc exposure in Chinese foundry workers. Am. J. Ind. Med. 1999, 35, 574-580.

27. Sturgis, C.C.; Drinker, P.; Thompson, R.M. Metal fume fever: I. Clinical observations on the effect of the experimental inhalation of zinc oxide by two apparently normal persons. J. Ind. Hyg. 1927, 9, 88-97.

28. Hammond, J.W. Metal fume fever in crushed stone industry. J. Ind. Hyg. 1944, 26, 117-119.

29. Blanc, P.; Wong, H.; Bernstein, M.S.; Boushey, H.A. An experimental human model of metal fume fever. Ann. Intern. Med. 1991, 114, 930-936.

30. Drinker, P.; Thompson, R.M.; Finn, J.L. Metal fume fever: IV. Threshold doses of zinc oxide, preventive measures, and the chronic effects of repeated exposures. J. Ind. Hyg. 1927, 9, 331-345.

31. Marquart, H.; Smid, T.; Heederik, D.; Visschers, M. Lung function of welders of zinc-coated mild steel: cross-sectional analysis and changes over five consecutive work shifts. Am. J. Ind. Med. 1989, 16, 289-296.

32. OSHA. Occupational Safety and Health Standards; Occupational Safety and Health Administration: Washington, DC, USA, 2003; Vol. 29 CFR 1910.1000, pp. Table Z-1.

33. Agren, M.S. Percutaneous absorption of zinc from zinc oxide applied topically to intact skin in man. Dermatologica 1990, 180, 36-39. 
34. Agren, M.S.; Krusell, M.; Franzen, L. Release and absorption of zinc from zinc oxide and zinc sulfate in open wounds. Acta Dermato.-Venereol. 1991, 71, 330-333.

35. Lansdown, A.B. Interspecies variations in response to topical application of selected zinc compounds. Food. Chem. Toxicol. 1991, 29, 57-64.

36. Agren, M.S.; Franzen, L.; Chvapil, M. Effects on wound healing of zinc oxide in a hydrocolloid dressing. J. Am. Acad. Dermatol. 1993, 29, 221-227.

37. Lansdown, A.B. Influence of zinc oxide in the closure of open skin wounds. Int. J. Cosmet. Sci. 1993, 15, 83-85.

38. Stromberg, H.E.; Agren, M.S. Topical zinc oxide treatment improves arterial and venous leg ulcers. Br. J. Dermatol. 1984, 111, 461-468.

39. Trumbo, P.; Yates, A.A.; Schlicker, S.; Poos, M. Dietary reference intakes: vitamin A, vitamin K, arsenic, boron, chromium, copper, iodine, iron, manganese, molybdenum, nickel, silicon, vanadium, and zinc. J. Am. Diet. Assoc. 2001, 101, 294-301.

40. Brown, M.A.; Thom, J.V.; Orth, G.L.; Cova, P.; Juarez, J. Food poisoning involving zinc contamination. Arch. Environ. Health 1964, 8, 657-660.

41. Fox, M.R.S. Zinc excess. In Zinc in Human Biology; Mills, C.F., Ed.; Springer Verlag: New York, NY, USA, 1989; pp. 366-368.

42. Porea, T.J.; Belmont, J.W.; Mahoney, D.H., Jr. Zinc-induced anemia and neutropenia in an adolescent. J. Pediatr. 2000, 136, 688-690.

43. Samman, S.; Roberts, D.C. The effect of zinc supplements on plasma zinc and copper levels and the reported symptoms in healthy volunteers. Med. J. Aust. 1987, 146, 246-249.

44. Haase, H.; Overbeck, S.; Rink, L. Zinc supplementation for the treatment or prevention of disease: current status and future perspectives. Exp. Gerontol. 2008, 43, 394-408.

45. Callender, G.R.; Gentzkow, C.J. Acute poisoning by the zinc and antimony content of limeade prepared in a galvanized iron can. Military Surgeon 1937, 80, 67-71.

46. Lewis, M.R.; Kokan, L. Zinc gluconate: acute ingestion. J. Toxicol. Clin. Toxicol. 1998, 36, 99-101.

47. Liu, C.H.; Lee, C.T.; Tsai, F.C.; Hsu, S.J.; Yang, P.M. Gastroduodenal corrosive injury after oral zinc oxide. Ann. Emerg. Med. 2006, 47, 296.

48. Magee, A.C.; Matrone, G. Studies on growth, copper metabolism of rats fed high levels of zinc. J. Nutr. 1960, 72, 233-242.

49. Ogiso, T.; Moriyama, K.; Sasaki, S.; Ishimura, Y.; Minato, A. Inhibitory effect of high dietary zinc on copper absorption in rats. Chem. Pharm. Bull. (Tokyo) 1974, 22, 55-60.

50. Van Campen, D.R. Copper interference with the intestinal absorption of zinc-65 by rats. J. Nutr. 1969, 97, 104-108.

51. Igic, P.G.; Lee, E.; Harper, W.; Roach, K.W. Toxic effects associated with consumption of zinc. Mayo. Clin. Proc. 2002, 77, 713-716.

52. Ogiso, T.; Ogawa, N.; Miura, T. Inhibitory effect of high dietary zinc on copper absorption in rats. II. Binding of copper and zinc to cytosol proteins in the intestinal mucosa. Chem. Pharm. Bull. 1979, 27, 515-521. 
53. Oestreicher, P.; Cousins, R.J. Copper and zinc absorption in the rat: mechanism of mutual antagonism. J. Nutr. 1985, 115, 159-166.

54. Fischer, P.W.; Giroux, A.; L'Abbe, M.R. The effect of dietary zinc on intestinal copper absorption. Am. J. Clin. Nutr. 1981, 34, 1670-1675.

55. Fiske, D.N.; McCoy, H.E., III; Kitchens, C.S. Zinc-induced sideroblastic anemia: report of a case, review of the literature, and description of the hematologic syndrome. Am. J. Hematol. 1994, 46, 147-150.

56. Prohaska, J.R. Biochemical changes in copper deficiency. J. Nutr. Biochem. 1990, 1, 452-461.

57. Sandstead, H.H. Requirements and toxicity of essential trace elements, illustrated by zinc and copper. Am. J. Clin. Nutr. 1995, 61, 621S-624S.

58. Irving, J.A.; Mattman, A.; Lockitch, G.; Farrell, K.; Wadsworth, L.D. Element of caution: a case of reversible cytopenias associated with excessive zinc supplementation. CMAJ 2003, 169, 129-131.

59. Prasad, A.S.; Brewer, G.J.; Schoomaker, E.B.; Rabbani, P. Hypocupremia induced by zinc therapy in adults. JAMA 1978, 240, 2166-2168.

60. Broun, E.R.; Greist, A.; Tricot, G.; Hoffman, R. Excessive zinc ingestion: a reversible cause of sideroblastic anemia and bone marrow depression. JAMA 1990, 265, 1441-1443.

61. Frieden, E. The copper connection. Semin. Hematol. 1983, 20, 114-117.

62. Willis, M.S.; Monaghan, S.A.; Miller, M.L.; McKenna, R.W.; Perkins, W.D.; Levinson, B.S.; Bhushan, V.; Kroft, S.H. Zinc-induced copper deficiency: a report of three cases initially recognized on bone marrow examination. Am. J. Clin. Pathol. 2005, 123, 125-131.

63. Williams, D.M. Copper deficiency in humans. Semin. Hematol. 1983, 20, 118-128.

64. Williams, D.M.; Lynch, R.E.; Lee, G.R.; Cartwright, G.E. Superoxide dismutase activity in copper-deficient swine. Proc. Soc. Exp. Biol. Med. 1975, 149, 534-536.

65. Foster, M.; Petocz, P.; Samman, S. Effects of zinc on plasma lipoprotein cholesterol concentrations in humans: A meta-analysis of randomised controlled trials. Atherosclerosis 2009, doi:10.1016/j.atherosclerosis.2009.11.038.

66. Black, M.R.; Medeiros, D.M.; Brunett, E.; Welke, R. Zinc supplements and serum lipids in young adult white males. Am. J. Clin. Nutr. 1988, 47, 970-975.

67. Hooper, P.L.; Visconti, L.; Garry, P.J.; Johnson, G.E. Zinc lowers high-density lipoproteincholesterol levels. JAMA 1980, 244, 1960-1961.

68. Freeland-Graves, J.H.; Friedman, B.J.; Han, W.H.; Shorey, R.L.; Young, R. Effect of zinc supplementation on plasma high-density lipoprotein cholesterol and zinc. Am. J. Clin. Nutr. 1982, 35, 988-992.

69. Reiser, S.; Powell, A.S.; Yang, C.; Canary, J. Effect of copper intake on blood cholesterol and its lipoprotein distribution in men. Nutr. Rep. Int. 1987, 36, 641-649.

70. Klevay, L.M.; Inman, L.; Johnson, L.K.; Lawler, M.; Mahalko, J.R.; Milne, D.B.; Lukaski, H.C.; Bolonchuk, W.; Sandstead, H.H. Increased cholesterol in plasma in a young man during experimental copper depletion. Metabolism 1984, 33, 1112-1118.

71. Beyersmann, D.; Hartwig, A. Carcinogenic metal compounds: recent insight into molecular and cellular mechanisms. Arch. Toxicol. 2008, 82, 493-512. 
72. Costello, L.C.; Franklin, R.B. Novel role of zinc in the regulation of prostate citrate metabolism and its implications in prostate cancer. Prostate 1998, 35, 285-296.

73. Habib, F.K. Zinc and the steroid endocrinology of the human prostate. J. Steroid. Biochem. 1978, 9, 403-407.

74. Zaichick, V.; Sviridova, T.V.; Zaichick, S.V. Zinc in the human prostate gland: normal, hyperplastic and cancerous. Int. Urol. Nephrol. 1997, 29, 565-574.

75. Costello, L.C.; Liu, Y.; Zou, J.; Franklin, R.B. Evidence for a zinc uptake transporter in human prostate cancer cells which is regulated by prolactin and testosterone. J. Biol. Chem. 1999, 274, 17499-17504.

76. Franklin, R.B.; Feng, P.; Milon, B.; Desouki, M.M.; Singh, K.K.; Kajdacsy-Balla, A.; Bagasra, O.; Costello, L.C. hZIP1 zinc uptake transporter down regulation and zinc depletion in prostate cancer. Mol. Cancer 2005, 4, 32.

77. Jarrard, D.F. Does zinc supplementation increase the risk of prostate cancer? Arch. Ophthalmol. 2005, 123, 102-103.

78. Leitzmann, M.F.; Stampfer, M.J.; Wu, K.; Colditz, G.A.; Willett, W.C.; Giovannucci, E.L. Zinc supplement use and risk of prostate cancer. J. Natl. Cancer Inst. 2003, 95, 1004-1007.

79. Honscheid, A.; Rink, L.; Haase, H. T-lymphocytes: a target for stimulatory and inhibitory effects of zinc ions. Endocr. Metab. Immune Disord. Drug Targets 2009, 9, 132-144.

80. Rink, L.; Gabriel, P. Zinc and the immune system. Proc. Nutr. Soc. 2000, 59, 541-552.

81. Delafuente, J.C. Nutrients and immune responses. Rheum. Dis. Clin. North Am. 1991, 17, 203-212.

82. Fraker, P.J.; DePasquale-Jardieu, P.; Zwickl, C.M.; Luecke, R.W. Regeneration of T-cell helper function in zinc-deficient adult mice. Proc. Nat. Acad. Sci. USA 1978, 75, 5660-5664.

83. Haase, H.; Rink, L. Functional significance of zinc-related signaling pathways in immune cells. Annu. Rev. Nutr. 2009, 29, 133-152.

84. Wellinghausen, N.; Driessen, C.; Rink, L. Stimulation of human peripheral blood mononuclear cells by zinc and related cations. Cytokine 1996, 8, 767-771.

85. Bulgarini, D.; Habetswallner, D.; Boccoli, G.; Montesoro, E.; Camagna, A.; Mastroberardino, G.; Rosania, C.; Testa, U.; Peschle, C. Zinc modulates the mitogenic activation of human peripheral blood lymphocytes. Ann. Ist. Super. Sanita. 1989, 25, 463-470.

86. Wellinghausen, N.; Martin, M.; Rink, L. Zinc inhibits interleukin-1-dependent T cell stimulation. Eur. J. Immunol. 1997, 27, 2529-2535.

87. Campo, C.A.; Wellinghausen, N.; Faber, C.; Fischer, A.; Rink, L. Zinc inhibits the mixed lymphocyte culture. Biol. Tr. Elem. Res. 2001, 79, 15-22.

88. Faber, C.; Gabriel, P.; Ibs, K.H.; Rink, L. Zinc in pharmacological doses suppresses allogeneic reaction without affecting the antigenic response. Bone Marrow Transplant. 2004, 33, 1241-1246.

89. Duchateau, J.; Delepesse, G.; Vrijens, R.; Collet, H. Beneficial effects of oral zinc supplementation on the immune response of old people. Am. J. Med. 1981, 70, 1001-1004.

90. Cummings, J.E.; Kovacic, J.P. The ubiquitous role of zinc in health and disease. J. Vet. Emerg. Crit. Care 2009, 19, 215-240. 
91. Formigari, A.; Irato, P.; Santon, A. Zinc, antioxidant systems and metallothionein in metal mediated-apoptosis: biochemical and cytochemical aspects. Comp. Biochem. Physiol. Pt. C 2007, $146,443-459$.

92. Haase, H.; Watjen, W.; Beyersmann, D. Zinc induces apoptosis that can be suppressed by lanthanum in C6 rat glioma cells. Biol. Chem. 2001, 382, 1227-1234.

93. Truong-Tran, A.Q.; Carter, J.; Ruffin, R.E.; Zalewski, P.D. The role of zinc in caspase activation and apoptotic cell death. Biometals 2001, 14, 315-330.

94. Fraker, P.J.; Telford, W.G. A reappraisal of the role of zinc in life and death decisions of cells. Proc. Soc. Exp. Biol. Med. 1997, 215, 229-236.

95. Watjen, W.; Haase, H.; Biagioli, M.; Beyersmann, D. Induction of apoptosis in mammalian cells by cadmium and zinc. Environ. Health Perspect. 2002, 110, 865-867.

96. Kim, Y.H.; Kim, E.Y.; Gwag, B.J.; Sohn, S.; Koh, J.Y. Zinc-induced cortical neuronal death with features of apoptosis and necrosis: mediation by free radicals. Neuroscience 1999, 89, 175-182.

97. McLaughlin, B.; Pal, S.; Tran, M.P.; Parsons, A.A.; Barone, F.C.; Erhardt, J.A.; Aizenman, E. p38 activation is required upstream of potassium current enhancement and caspase cleavage in thiol oxidant-induced neuronal apoptosis. J. Neurosci. 2001, 21, 3303-3311.

98. Wiseman, D.A.; Wells, S.M.; Wilham, J.; Hubbard, M.; Welker, J.E.; Black, S.M. Endothelial response to stress from exogenous $\mathrm{Zn}^{2+}$ resembles that of NO-mediated nitrosative stress, and is protected by MT-1 overexpression. Am. J. Physiol. Cell Physiol. 2006, 291, C555-568.

99. Brown, A.M.; Kristal, B.S.; Effron, M.S.; Shestopalov, A.I.; Ullucci, P.A.; Sheu, K.F.; Blass, J.P.; Cooper, A.J. $\mathrm{Zn}^{2+}$ inhibits alpha-ketoglutarate-stimulated mitochondrial respiration and the isolated alpha-ketoglutarate dehydrogenase complex. J. Biol. Chem. 2000, 275, 13441-13447.

100. Sheline, C.T.; Behrens, M.M.; Choi, D.W. Zinc-induced cortical neuronal death: contribution of energy failure attributable to loss of $\mathrm{NAD}(+)$ and inhibition of glycolysis. J. Neurosci. 2000, 20, 3139-3146.

101. Feng, P.; Li, T.; Guan, Z.; Franklin, R.B.; Costello, L.C. The involvement of Bax in zinc-induced mitochondrial apoptogenesis in malignant prostate cells. Mol. Cancer 2008, 7, 25.

102. Dineley, K.E.; Votyakova, T.V.; Reynolds, I.J. Zinc inhibition of cellular energy production: implications for mitochondria and neurodegeneration. J. Neurochem. 2003, 85, 563-570.

103. Feng, P.; Li, T.L.; Guan, Z.X.; Franklin, R.B.; Costello, L.C. Direct effect of zinc on mitochondrial apoptogenesis in prostate cells. Prostate 2002, 52, 311-318.

104. Mills, D.A.; Schmidt, B.; Hiser, C.; Westley, E.; Ferguson-Miller, S. Membrane potentialcontrolled inhibition of cytochrome c oxidase by zinc. J. Biol. Chem. 2002, 277, 14894-14901.

105. Bitanihirwe, B.K.; Cunningham, M.G. Zinc: the brain's dark horse. Synapse 2009, 63, 1029-1049.

106. Cui, L.; Takagi, Y.; Sando, K.; Wasa, M.; Okada, A. Nitric oxide synthase inhibitor attenuates inflammatory lesions in the skin of zinc-deficient rats. Nutrition 2000, 16, 34-41.

107. Cui, L.; Takagi, Y.; Wasa, M.; Sando, K.; Khan, J.; Okada, A. Nitric oxide synthase inhibitor attenuates intestinal damage induced by zinc deficiency in rats. J. Nutr. 1999, 129, 792-798.

108. Oteiza, P.I.; Clegg, M.S.; Zago, M.P.; Keen, C.L. Zinc deficiency induces oxidative stress and AP-1 activation in 3T3 cells. Free Radical Biol. Med. 2000, 28, 1091-1099. 
109. Williams, R.J.P. The biochemistry of zinc. Polyhedron 1987, 6, 61-69.

110. Perry, D.K.; Smyth, M.J.; Stennicke, H.R.; Salvesen, G.S.; Duriez, P.; Poirier, G.G.; Hannun, Y.A. Zinc is a potent inhibitor of the apoptotic protease, caspase-3. A novel target for zinc in the inhibition of apoptosis. J. Biol. Chem. 1997, 272, 18530-18533.

111. Maret, W.; Jacob, C.; Vallee, B.L.; Fischer, E.H. Inhibitory sites in enzymes: zinc removal and reactivation by thionein. Proc. Nat. Acad. Sci. USA 1999, 96, 1936-1940.

112. Stennicke, H.R.; Salvesen, G.S. Biochemical characteristics of caspases-3, -6, -7, and -8. J. Biol. Chem. 1997, 272, 25719-25723.

113. Clegg, M.S.; Hanna, L.A.; Niles, B.J.; Momma, T.Y.; Keen, C.L. Zinc deficiency-induced cell death. IUBMB Life 2005, 57, 661-669.

114. Fukamachi, Y.; Karasaki, Y.; Sugiura, T.; Itoh, H.; Abe, T.; Yamamura, K.; Higashi, K. Zinc suppresses apoptosis of U937 cells induced by hydrogen peroxide through an increase of the Bcl-2/Bax ratio. Biochem. Biophys. Res. Commun. 1998, 246, 364-369.

115. Zalewski, P.D.; Forbes, I.J.; Giannakis, C. Physiological role for zinc in prevention of apoptosis (gene-directed death). Biochem. Int. 1991, 24, 1093-1101.

116. Zalewski, P.D.; Forbes, I.J.; Betts, W.H. Correlation of apoptosis with change in intracellular labile $\mathrm{Zn}$ (II) using zinquin [(2-methyl-8-p-toluenesulphonamido-6-quinolyloxy)acetic acid], a new specific fluorescent probe for $\mathrm{Zn}(\mathrm{II})$. Biochem. J. 1993, 296, 403-408.

117. Murphy, J.V. Intoxication following ingestion of elemental zinc. JAMA 1970, 212, 2119-2120.

118. Colvin, R.A.; Fontaine, C.P.; Laskowski, M.; Thomas, D. $\mathrm{Zn}^{2+}$ transporters and $\mathrm{Zn}^{2+}$ homeostasis in neurons. Eur. J. Pharmacol. 2003, 479, 171-185.

119. Frederickson, C.J.; Bush, A.I. Synaptically released zinc: physiological functions and pathological effects. Biometals 2001, 14, 353-366.

120. Takeda, A. Movement of zinc and its functional significance in the brain. Brain. Res. Rev. 2000, 34, 137-148.

121. Vogt, K.; Mellor, J.; Tong, G.; Nicoll, R. The actions of synaptically released zinc at hippocampal mossy fiber synapses. Neuron 2000, 26, 187-196.

122. Cuajungco, M.P.; Lees, G.J. Zinc and Alzheimer's disease: is there a direct link? Brain. Res. Rev. 1997, 23, 219-236.

123. Cuajungco, M.P.; Lees, G.J. Zinc metabolism in the brain: relevance to human neurodegenerative disorders. Neurobiol. Disease 1997, 4, 137-169.

124. Frederickson, C.J.; Suh, S.W.; Silva, D.; Thompson, R.B. Importance of zinc in the central nervous system: the zinc-containing neuron. J. Nutr. 2000, 130, 1471S-1483S.

125. Duncan, M.W.; Marini, A.M.; Watters, R.; Kopin, I.J.; Markey, S.P. Zinc, a neurotoxin to cultured neurons, contaminates cycad flour prepared by traditional guamanian methods. $J$. Neurosci. 1992, 12, 1523-1537.

126. Choi, D.W.; Yokoyama, M.; Koh, J. Zinc neurotoxicity in cortical cell culture. Neuroscience 1988, 24, 67-79.

127. Frederickson, C.J. Neurobiology of zinc and zinc-containing neurons. Int. Rev. Neurobiol. 1989, $31,145-238$. 
128. Koh, J.Y.; Choi, D.W. Zinc toxicity on cultured cortical neurons: involvement of N-methyl-Daspartate receptors. Neuroscience 1994, 60, 1049-1057.

129. Wang, Y.X.; Quastel, D.M. Multiple actions of zinc on transmitter release at mouse end-plates. Pflugers. Arch.-Eur. J. Physiol. 1990, 415, 582-587.

130. Colvin, R.A.; Davis, N.; Nipper, R.W.; Carter, P.A. Zinc transport in the brain: routes of zinc influx and efflux in neurons. J. Nutr. 2000, 130, 1484S-1487S.

131. Weiss, J.H.; Hartley, D.M.; Koh, J.Y.; Choi, D.W. AMPA receptor activation potentiates zinc neurotoxicity. Neuron 1993, 10, 43-49.

132. Yin, H.Z.; Weiss, J.H. $\mathrm{Zn}(2+)$ permeates $\mathrm{Ca}(2+)$ permeable AMPA/kainate channels and triggers selective neural injury. Neuroreport 1995, 6, 2553-2556.

133. Sensi, S.L.; Ton-That, D.; Weiss, J.H. Mitochondrial sequestration and $\mathrm{Ca}(2+)$-dependent release of cytosolic $\mathrm{Zn}(2+)$ loads in cortical neurons. Neurobiol. Disease 2002, 10, 100-108.

134. Masters, B.A.; Quaife, C.J.; Erickson, J.C.; Kelly, E.J.; Froelick, G.J.; Zambrowicz, B.P.; Brinster, R.L.; Palmiter, R.D. Metallothionein III is expressed in neurons that sequester zinc in synaptic vesicles. J. Neurosci. 1994, 14, 5844-5857.

135. Palmiter, R.D.; Findley, S.D.; Whitmore, T.E.; Durnam, D.M. MT-III, a brain-specific member of the metallothionein gene family. Proc. Nat. Acad. Sci. USA 1992, 89, 6333-6337.

136. Yokoyama, M.; Koh, J.; Choi, D.W. Brief exposure to zinc is toxic to cortical neurons. Neurosci. Lett. 1986, 71, 351-355.

137. Frederickson, C.J.; Klitenick, M.A.; Manton, W.I.; Kirkpatrick, J.B. Cytoarchitectonic distribution of zinc in the hippocampus of man and the rat. Brain. Res. 1983, 273, 335-339.

138. Assaf, S.Y.; Chung, S.H. Release of endogenous $\mathrm{Zn} 2+$ from brain tissue during activity. Nature 1984, 308, 734-736.

139. Sloviter, R.S. A selective loss of hippocampal mossy fiber Timm stain accompanies granule cell seizure activity induced by perforant path stimulation. Brain. Res. 1985, 330, 150-153.

140. Siesjo, B.K. Basic mechanisms of traumatic brain damage. Ann. Emerg. Med. 1993, 22, 959-969.

141. Frederickson, C.J.; Koh, J.Y.; Bush, A.I. The neurobiology of zinc in health and disease. Nat. Rev. Neurosci. 2005, 6, 449-462.

142. Choi, D.W.; Koh, J.Y. Zinc and brain injury. Annu. Rev. Neurosci. 1998, 21, 347-375.

143. Weiss, J.H.; Sensi, S.L.; Koh, J.Y. Zn(2+): a novel ionic mediator of neural injury in brain disease. Trends. Pharmacol. Sci. 2000, 21, 395-401.

144. Tonder, N.; Johansen, F.F.; Frederickson, C.J.; Zimmer, J.; Diemer, N.H. Possible role of zinc in the selective degeneration of dentate hilar neurons after cerebral ischemia in the adult rat. Neurosci. Lett. 1990, 109, 247-252.

145. Koh, J.Y.; Suh, S.W.; Gwag, B.J.; He, Y.Y.; Hsu, C.Y.; Choi, D.W. The role of zinc in selective neuronal death after transient global cerebral ischemia. Science 1996, 272, 1013-1016.

146. Suh, S.W.; Chen, J.W.; Motamedi, M.; Bell, B.; Listiak, K.; Pons, N.F.; Danscher, G.; Frederickson, C.J. Evidence that synaptically-released zinc contributes to neuronal injury after traumatic brain injury. Brain. Res. 2000, 852, 268-273. 
147. Lee, J.Y.; Cole, T.B.; Palmiter, R.D.; Koh, J.Y. Accumulation of zinc in degenerating hippocampal neurons of ZnT3-null mice after seizures: evidence against synaptic vesicle origin. J. Neurosci. 2000, 20, RC79.

148. Jiang, D.; Sullivan, P.G.; Sensi, S.L.; Steward, O.; Weiss, J.H. Zn(2+) induces permeability transition pore opening and release of pro-apoptotic peptides from neuronal mitochondria. $J$. Biol. Chem. 2001, 276, 47524-47529.

149. Sensi, S.L.; Ton-That, D.; Sullivan, P.G.; Jonas, E.A.; Gee, K.R.; Kaczmarek, L.K.; Weiss, J.H. Modulation of mitochondrial function by endogenous Zn2+ pools. Proc. Nat. Acad. Sci. USA 2003, 100, 6157-6162.

150. Kim, E.Y.; Koh, J.Y.; Kim, Y.H.; Sohn, S.; Joe, E.; Gwag, B.J. Zn ${ }^{2+}$ entry produces oxidative neuronal necrosis in cortical cell cultures. Eur. J. Neurosci. 1999, 11, 327-334.

151. Sensi, S.L.; Yin, H.Z.; Weiss, J.H. Glutamate triggers preferential $\mathrm{Zn}^{2+}$ flux through $\mathrm{Ca}^{2+}$ permeable AMPA channels and consequent ROS production. Neuroreport 1999, 10, 1723-1727.

152. Noh, K.M.; Koh, J.Y. Induction and activation by zinc of NADPH oxidase in cultured cortical neurons and astrocytes. J. Neurosci. 2000, 20, RC111.

153. Seo, S.R.; Chong, S.A.; Lee, S.I.; Sung, J.Y.; Ahn, Y.S.; Chung, K.C.; Seo, J.T. $\mathrm{Zn}^{2+}$-induced ERK activation mediated by reactive oxygen species causes cell death in differentiated PC12 cells. J. Neurochem. 2001, 78, 600-610.

154. Aizenman, E.; Stout, A.K.; Hartnett, K.A.; Dineley, K.E.; McLaughlin, B.; Reynolds, I.J. Induction of neuronal apoptosis by thiol oxidation: putative role of intracellular zinc release. $J$. Neurochem. 2000, 75, 1878-1888.

155. Wei, G.; Hough, C.J.; Li, Y.; Sarvey, J.M. Characterization of extracellular accumulation of $\mathrm{Zn}^{2+}$ during ischemia and reperfusion of hippocampus slices in rat. Neuroscience 2004, 125, 867-877.

156. Frederickson, C.J.; Cuajungco, M.P.; LaBuda, C.J.; Suh, S.W. Nitric oxide causes apparent release of zinc from presynaptic boutons. Neuroscience 2002, 115, 471-474.

157. Park, J.A.; Lee, J.Y.; Sato, T.A.; Koh, J.Y. Co-induction of p75NTR and p75NTR-associated death executor in neurons after zinc exposure in cortical culture or transient ischemia in the rat. $J$. Neurosci. 2000, 20, 9096-9103.

158. Mukai, J.; Hachiya, T.; Shoji-Hoshino, S.; Kimura, M.T.; Nadano, D.; Suvanto, P.; Hanaoka, T.; Li, Y.; Irie, S.; Greene, L.A.; Sato, T.A. NADE, a p75NTR-associated cell death executor, is involved in signal transduction mediated by the common neurotrophin receptor p75NTR. J. Biol. Chem. 2000, 275, 17566-17570.

159. Lobner, D.; Canzoniero, L.M.; Manzerra, P.; Gottron, F.; Ying, H.; Knudson, M.; Tian, M.; Dugan, L.L.; Kerchner, G.A.; Sheline, C.T.; Korsmeyer, S.J.; Choi, D.W. Zinc-induced neuronal death in cortical neurons. Cell. Mol. Biol. 2000, 46, 797-806.

160. Manev, H.; Kharlamov, E.; Uz, T.; Mason, R.P.; Cagnoli, C.M. Characterization of zinc-induced neuronal death in primary cultures of rat cerebellar granule cells. Exp. Neurol. 1997, 146, 171-178.

161. Barkalifa, R.; Hershfinkel, M.; Friedman, J.E.; Kozak, A.; Sekler, I. The lipophilic zinc chelator DP-b99 prevents zinc induced neuronal death. Eur. J. Pharmacol. 2009, 618, 15-21. 
162. Devirgiliis, C.; Zalewski, P.D.; Perozzi, G.; Murgia, C. Zinc fluxes and zinc transporter genes in chronic diseases. Mutat. Res. 2007, 622, 84-93.

163. Sensi, S.L.; Paoletti, P.; Bush, A.I.; Sekler, I. Zinc in the physiology and pathology of the CNS. Nat. Rev. Neurosci. 2009, 10, 780-791.

164. Ackland, M.L.; Michalczyk, A. Zinc deficiency and its inherited disorders: a review. Genes. Nutr. 2006, 1, 41-49.

165. Prasad, A.S. Clinical manifestations of zinc deficiency. Annu. Rev. Nutr. 1985, 5, 341-363.

166. Prasad, A.S.; Halsted, J.A.; Nadimi, M. Syndrome of iron deficiency anemia, hepatosplenomegaly, hypogonadism, dwarfism and geophagia. Am. J. Med. 1961, 31, 532-546.

167. Prasad, A.S.; Miale, A.J.; Farid, Z.; Sandstead, H.H.; Schulert, A.R. Zinc metabolism in patients with the symptoms of iron deficiency, anaemia, hepatosplenomegaly, dwarfism and hypogonadism. J. Lab. Clin. Med. 1963, 61, 537-549.

168. Sandstead, H.H. Zinc deficiency. A public health problem? Am. J. Dis. Child 1991, 145, 853-859.

169. Wang, K.; Zhou, B.; Kuo, Y.M.; Zemansky, J.; Gitschier, J. A novel member of a zinc transporter family is defective in acrodermatitis enteropathica. Am. J. Hum. Genet. 2002, 71, 66-73.

170. Aggett, P.J. Acrodermatitis enteropathica. J. Inherit. Metab. Dis. 1983, 6, 39-43.

171. Failla, M.L.; van de Veerdonk, M.; Morgan, W.T.; Smith, J.C., Jr. Characterization of zincbinding proteins of plasma in familial hyperzincemia. J. Lab. Clin. Med. 1982, 100, 943-952.

172. Fessatou, S.; Fagerhol, M.K.; Roth, J.; Stamoulakatou, A.; Kitra, V.; Hadarean, M.; Paleologos, G.; Chandrinou, H.; Sampson, B.; Papassotiriou, I. Severe anemia and neutropenia associated with hyperzincemia and hypercalprotectinemia. J. Pediatr. Hematol. Oncol. 2005, 27, 477-480.

173. Smith, J.C.; Zeller, J.A.; Brown, E.D.; Ong, S.C. Elevated plasmz zinc: a heritable anomaly. Science 1976, 193, 496-498.

174. Saito, Y.; Saito, K.; Hirano, Y.; Ikeya, K.; Suzuki, H.; Shishikura, K.; Manno, S.; Takakuwa, Y.; Nakagawa, K.; Iwasa, A.; Fujikawa, S.; Moriya, M.; Mizoguchi, N.; Golden, B.E.; Osawa, M. Hyperzincemia with systemic inflammation: a heritable disorder of calprotectin metabolism with rheumatic manifestations? J. Pediatr. 2002, 140, 267-269.

175. Sampson, B.; Kovar, I.Z.; Rauscher, A.; Fairweather-Tait, S.; Beattie, J.; McArdle, H.J.; Ahmed, R.; Green, C. A case of hyperzincemia with functional zinc depletion: a new disorder? Pediatr. Res. 1997, 42, 219-225.

176. Prasad, A.S. Zinc deficiency and effects of zinc supplementation on sickle cell anemia subjects. Prog. Clin. Biol. Res. 1981, 55, 99-122.

177. Prasad, A.S. Zinc deficiency in patients with sickle cell disease. Am. J. Clin. Nutr. 2002, 75, 181-182.

178. Dardenne, M.; Savino, W.; Wade, S.; Kaiserlian, D.; Lemonnier, D.; Bach, J.F. In vivo and in vitro studies of thymulin in marginally zinc-deficient mice. Eur. J. Immunol. 1984, 14, 454-458.

179. Wuehler, S.E.; Peerson, J.M.; Brown, K.H. Use of national food balance data to estimate the adequacy of zinc in national food supplies: methodology and regional estimates. Public Health Nutr. 2005, 8, 812-819. 
180. Cavdar, A.O.; Arcasoy, A.; Cin, S.; Babacan, E.; Gozdasoglu, S. Geophagia in Turkey: iron and zinc deficiency, iron and zinc absorption studies and response to treatment with zinc in geophagia cases. Prog. Clin. Biol. Res. 1983, 129, 71-97.

181. Cavdar, O.A. Zinc deficiency and geophagia. J. Pediatr. 1982, 100, 1003-1004.

182. Prasad, A.S.; Miale, A., Jr.; Farid, Z.; Sandstead, H.H.; Schulert, A.R. Zinc metabolism in patients with the syndrome of iron deficiency anemia, hepatosplenomegaly, dwarfism, and hypognadism. J. Lab. Clin. Med. 1963, 61, 537-549.

183. Briefel, R.R.; Bialostosky, K.; Kennedy-Stephenson, J.; McDowell, M.A.; Ervin, R.B.; Wright, J.D. Zinc intake of the U.S. population: findings from the third National Health and Nutrition Examination Survey, 1988-1994. J. Nutr. 2000, 130, 1367S-1373S.

(C) 2010 by the authors; licensee Molecular Diversity Preservation International, Basel, Switzerland. This article is an open-access article distributed under the terms and conditions of the Creative Commons Attribution license (http://creativecommons.org/licenses/by/3.0/). 